\title{
Morpho-Functional Consequences of Swiss Cheese Knockdown in Glia of Drosophila melanogaster
}

\author{
Elena V. Ryabova ${ }^{1}$, Pavel A. Melentev ${ }^{1}{ }^{1}$, Artem E. Komissarov ${ }^{1}$, Nina V. Surina ${ }^{1}$, Ekaterina A. Ivanova ${ }^{1}$, \\ Natalia Matiytsiv ${ }^{2}{ }^{(\mathbb{B}}$, Halyna R. Shcherbata ${ }^{3}{ }^{-1}$ and Svetlana V. Sarantseva ${ }^{1, *}$ \\ 1 Molecular and Radiation Biophysics Division, Petersburg Nuclear Physics Institute Named by \\ B.P.Konstantinov of NRC «Kurchatov Institute», 188300 Gatchina, Russia; ryabova_ev@pnpi.nrcki.ru (E.V.R.); \\ melentev_pa@pnpi.nrcki.ru (P.A.M.); komissarov_ae@pnpi.nrcki.ru (A.E.K.); \\ surina_nv@pnpi.nrcki.ru (N.V.S.); katya-i.ivanova@yandex.ru (E.A.I.) \\ 2 Department of Genetics and Biotechnology, Faculty of Biology, Ivan Franko Lviv National University, \\ 79005 Lviv, Ukraine; nataliya.matiytsiv@lnu.edu.ua \\ 3 Institute of Cell Biochemistry, Hannover Medical School, Carl-Neuberg-Strasse 1, 30625 Hannover, Germany; \\ Shcherbata.Halyna@mh-hannover.de \\ * Correspondence: Sarantseva_SV@pnpi.nrcki.ru
}

check for updates

Citation: Ryabova, E.V.; Melentev, P.A.; Komissarov, A.E.; Surina, N.V.; Ivanova, E.A.; Matiytsiv, N.;

Shcherbata, H.R.; Sarantseva, S.V. Morpho-Functional Consequences of Swiss Cheese Knockdown in Glia of Drosophila melanogaster. Cells 2021, 10, 529. https://doi.org/10.3390/ cells10030529

Academic Editor: S. Thameem Dheen

Received: 25 January 2021

Accepted: 24 February 2021

Published: 2 March 2021

Publisher's Note: MDPI stays neutral with regard to jurisdictional claims in published maps and institutional affiliations.

Copyright: (c) 2021 by the authors. Licensee MDPI, Basel, Switzerland. This article is an open access article distributed under the terms and conditions of the Creative Commons Attribution (CC BY) license (https:/ / creativecommons.org/licenses/by/ $4.0 /)$.

\begin{abstract}
Glia are crucial for the normal development and functioning of the nervous system in many animals. Insects are widely used for studies of glia genetics and physiology. Drosophila melanogaster surface glia (perineurial and subperineurial) form a blood-brain barrier in the central nervous system and blood-nerve barrier in the peripheral nervous system. Under the subperineurial glia layer, in the cortical region of the central nervous system, cortex glia encapsulate neuronal cell bodies, whilst in the peripheral nervous system, wrapping glia ensheath axons of peripheral nerves. Here, we show that the expression of the evolutionarily conserved swiss cheese gene is important in several types of glia. swiss cheese knockdown in subperineurial glia leads to morphological abnormalities of these cells. We found that the number of subperineurial glia nuclei is reduced under swiss cheese knockdown, possibly due to apoptosis. In addition, the downregulation of swiss cheese in wrapping glia causes a loss of its integrity. We reveal transcriptome changes under swiss cheese knockdown in subperineurial glia and in cortex + wrapping glia and show that the downregulation of swiss cheese in these types of glia provokes reactive oxygen species acceleration. These results are accompanied by a decline in animal mobility measured by the negative geotaxis performance assay.
\end{abstract}

Keywords: swiss cheese; NTE; PNPLA6; Drosophila melanogaster; glia; blood-brain barrier; nervous system; ROS; oxidative stress

\section{Introduction}

The swiss cheese (sws) gene of Drosophila melanogaster is evolutionarily conserved and its orthologues are found in a wide range of organisms, from bacteria to mammals [1]. Mutations in the swiss cheese orthologue gene in humans-NTE-lead to different diseases, including organophosphate-induced delayed neuropathy (OPIDN); hereditary spastic paraplegia type 39; pure cerebellar ataxia; ataxia with spasticity; and rare syndromes, such as Gordon Holmes, Boucher-Neuhäuser and Oliver McFarlane syndromes [2-5]. The sws gene encodes a protein with phospholipase B activity that is involved in phosphatidylcholine metabolism [6]. The SWS protein can also function as a regulator of the PKA-C3 catalytic subunit of protein kinase A [7,8]. Mutations in sws lead to age-dependent neurodegeneration, the structural alteration of glia cells, and a reduced insect life span $[9,10]$. SWS is widely expressed in nerve and glial cells $[9,10]$. The specific subtypes of glial cells that require SWS were formerly identified $[9,11]$. However, the role of SWS in glial cells that form barriers in the Drosophila nervous system is not fully clear.

Unlike the vascularized brain of vertebrates, the nervous system of invertebrates is surrounded by hemolymph, which transfers nutrients and factors through an organism. 
The selective transfer of various molecules from extracellular fluid to the nervous system is performed by blood barriers: The blood-brain barrier (BBB) in the central nervous system (CNS) and blood-nerve barrier (BNB) in the peripheral nervous system (PNS). Both barriers of Drosophila melanogaster cover the whole volume of the nervous system, protecting it from high ion concentrations, especially potassium, an elevated level of which can disrupt regulated electrical conductance [12,13]. The barrier of insects, both functionally and morphologically, resembles the cellular barrier of simple vertebrates $[12,14,15]$.

Both barriers of Drosophila consist of two sheet-like types of surface glia: perineurial (PG) and subperineurial (SPG) [16-18]. The first one is characterized by small sized cells and prolonged nuclei [8]. The specific function of PG has not yet been identified, but PG seems to maintain the integrity of BBB [18]. Additionally, during the larval stage, PG cells continuously divide and form intercellular junctions among themselves, thereby forming a layer covering the SPG [19]. Therefore, it is assumed that PG somehow influences the development and/or tightness of SPG [15]. PG cells resemble mammalian plasmatic astrocytes that are known to form a specific structure filling a big area of capillaries with its processes [14]. The PG layer also performs a barrier function, as large molecules, such as $500 \mathrm{kDa}$ dextran can be stopped by the outer layer of the surface glia [15].

The functional SPG barrier forms very early, during embryogenesis [15]. The SPG population is small and represents only $2 \%$ of all glia in the organism [18]. It is formed of big square-shaped polyploid cells, and their growth occurs during insect development accompanied by both endomitosis and endoreplication. Importantly, both of these processes ensure a lifelong BBB function and integrity [20]. For instance, the increased ploidy observed under Ntan1 dysfunction leads to nerve bulge formation accompanied by defasciculated axons in peripheral nerves in the 3rd instar larvae. A high Ntan1 level is necessary for the restriction of the cell cycle and replication rates during larval brain development [21]. This indicates that there is a correlation between the polyploidization level, cell size, and number of nuclei of SPG during insect development. SPG cells form septate junctions that are crucial for the SPG barrier function [22-25]. It was previously shown that there are some proteins that influence septate junctions of the Drosophila cellular barrier, and these factors are vital for BBB development at the embryonic stage. For instance, the dysfunction of claudin-like proteins, such as sinuous and pickle, alters the BBB permeability [15].

In the central nervous system, cortex glia (CG) form the cell layer that lies under SPG (Figure 1A). CG function similarly to astrocytes in mammals [19]. In insects, CG cells encapsulate neurons, thereby insulating them from each other and forming a honeycomblike cortex structure. Furthermore, CG ensheath neuronal processes before intersection of the neuropil [18]. In addition, CG provide neurons with nutrients and gaseous substances. A single CG cell can serve up to 100 neuron bodies [15]. SPG and CG interact tightly with each other through adherens junctions. It has been shown that it is the CG layer that interacts with SPG and accumulates a great amount of lipid droplets [26].

In peripheral nerves, wrapping glia (WG) are located under the SPG layer (Figure 1B). Their function in Drosophila is similar to that of mammalian non-myelinating Schwann cells. WG maintain neuronal nutrition and help to reduce electric noise between individual axons and prevent ephaptic coupling. Several WG cells can already be detected during embryonic development. After embryogenesis, WG cells begin to differentiate [27]. Disturbances in the development of WG affect the normal functioning of the nervous system [28].

Various genes have been found to regulate the survival and functioning of different glia types [21,29-31]. Among them, swiss cheese (sws) was shown to be important for SPG and ensheathing glia in the CNS neuropile. The knockdown (KD) of sws in SPG resulted in CNS vacuolization and locomotor activity disturbance [11]. Additionally, it was initially shown that in newly enclosed sws mutant flies, glia undergo hyperwrapping $[9,32]$.

In this study, we analyzed the role of sws in CNS and PNS glia subtypes at several stages of Drosophila melanogaster development. 


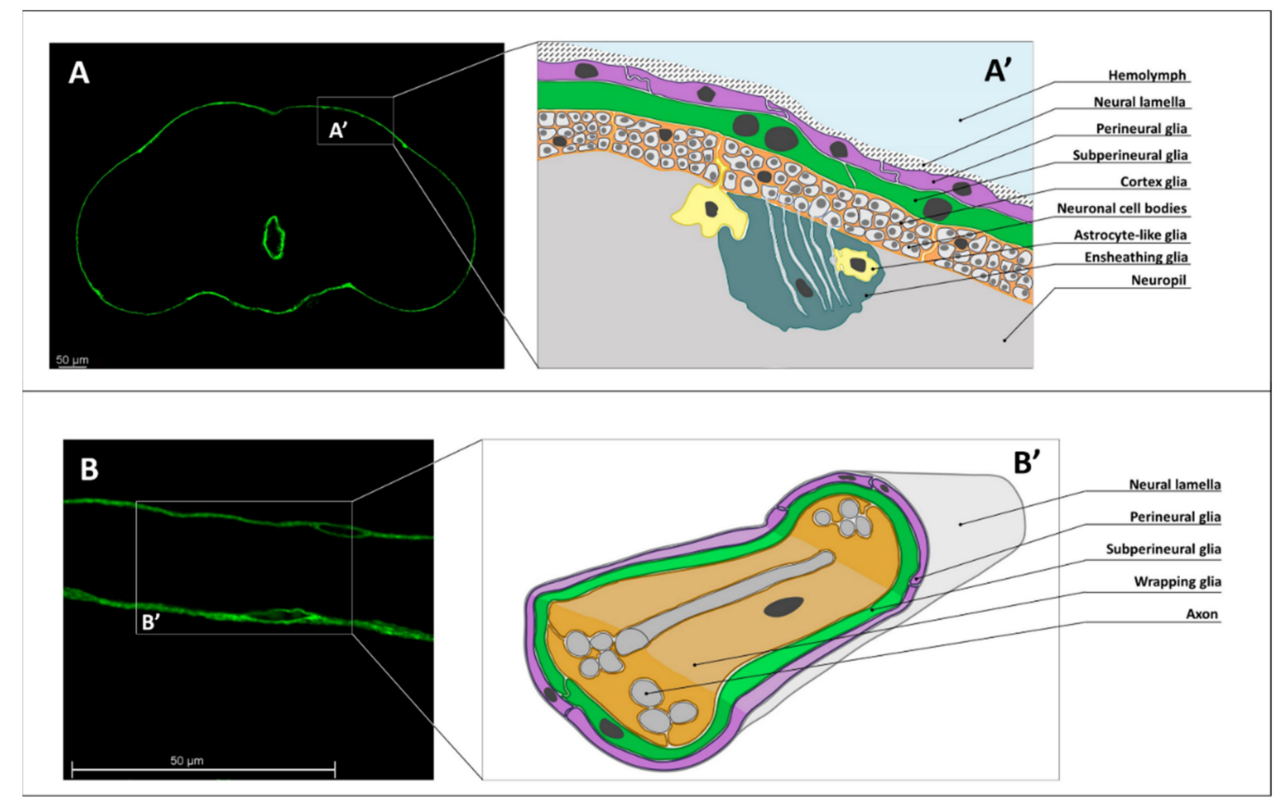

Figure 1. Types of glia in the Drosophila melanogaster nervous system. (A) Visualization of the Drosophila subperineurial glia (SPG) in the central nervous system (CNS) (confocal microscopy image of a brain, where SPG is marked with green fluorescent protein (GFP) in the NPS-GAL4;UAS-CD8-GFP genotype). (A') Scheme of the principal Drosophila brain cellular structure though a cross-section view, where SPG is shown in green, PG is shown in purple, WG is shown in orange. (B) Visualization of the Drosophila subperineurial glia in the peripheral nervous system (PNS) (confocal microscopy image of an abdominal nerve, where SPG is marked with GFP in the NPS-GAL4;UAS-CD8-GFP genotype). (B') Scheme of the principal Drosophila peripheral nerve cellular structure through a three-dimensional cross-section view, where SPG is shown in green, $\mathrm{PG}$ is shown in purple, WG is shown in orange. Scale bar: $50 \mu \mathrm{m}$.

\section{Materials and Methods}

\subsection{Drosophila Stocks}

To downregulate sws, an RNA-interference-induced approach was used to knockdown (KD) sws gene expression in different types of glial cells (UAS-sws-RNAi, BDSC 61338): panglially, repo-GAL4 (BDSC 7415); in perineurial glia, NP6293-GAL4 (hereinafter NPP-GAL4, KYOTO DGGR 105188); in subperineurial glia, NP2276-GAL4 (hereinafter NPS-GAL4, KYOTO DGGR 112853); and in both cortex and wrapping glia, NP2222-GAL4 (hereinafter NPC-GAL4, KYOTO DGGR 112830). Auxiliary fly stocks were used to visualize glia using membrane GFP (UAS-CD8-GFP, BDSC 8746) and DsRed protein with nuclear localization (UAS-RedStinger, BDSC 8547). Additionally, we used own promotor of sws to activate GAL4 expression in cells where sws is expressed (sws-GAL4, KYOTO DGGR 104592). UAS-NTE stock (kindly donated by Robert Wessells) was used to induce human NTE gene expression in the rescue experiment. All flies were kept at $+25^{\circ} \mathrm{C}$ in a standard semolina-yeast-sugar medium.

This study was approved by the Ethical Committee of the Petersburg Nuclear Physics Institute named by B.P. Konstantinov of NRC «Kurchatov Institute» (protocol \# 01/КПБof 13 January 2020).

\subsection{Nervous System Preparation for Confocal Microscopy}

Dissection was performed in phosphate-buffered saline (PBS), and larvae were fixed in 4\% paraformaldehyde (PanReac AppliChem, Spain) for $20 \mathrm{~min}$. Then, samples were washed three times in PBS for $5 \mathrm{~min}$ and stored in an antifade mounting medium for fluorescent samples (Vectashield, Vector Laboratories, USA).

Brain and ventral nerve cords of adult flies were dissected and fixed in freshly prepared $4 \%$ paraformaldehyde for $10 \mathrm{~min}$. Next, they were washed in PBS $3 \times 5$ min and placed in a medium for fluorescent microscopy (Vectashield, Vector Laboratories, USA). 


\subsection{Imaging and Analysis}

Series of images (2- $\mu \mathrm{m}$-thick) were obtained with a Leica LX laser confocal microscope (Leica microsystems, Germany) using $20 \times$ (air) and $63 \times$ (oil) objectives. A quantitative analysis was performed using the ImageJ software (NIH, USA). For a quantitative nuclei calculation and morphological analysis of glial cells, 25 flies were analyzed per genotype.

Confocal images were processed with ImageJ. The standard method for calculating the particle size was used. Three-dimensional (3D) reconstructions of pictures were created in Leica LasX software. The minimal size of $10 \mu \mathrm{m}^{2}$ was selected for identifying normal SPG nuclei. For PG and CG, a minimal size of $3 \mu \mathrm{m}^{2}$ was selected. Figures and illustrations were prepared in Leica LasX and Adobe Photoshop CC 2019 (Adobe, USA) (Supplementary Figure S1). For an analysis of small SPG nuclei, which we propose are fragmented, a minimal size of $5 \mu \mathrm{m}^{2}$ was chosen for particle quantification (Supplementary Figure S2).

\subsection{Immunohistochemistry}

Dissected brains were fixed for $40 \mathrm{~min}$ in $4 \%$ paraformaldehyde at room temperature (RT), washed $3 \times 5 \mathrm{~min}$ in PBS, and stained overnight at $+4^{\circ} \mathrm{C}$ with primary anti-repo (8D12, Developmental Studies Hybridoma Bank (DSHB), USA) antibodies diluted in blocking buffer (1:50). After washing them in PBS three times, samples were stained for $2 \mathrm{~h}$ at RT with a secondary Cy3 antibody (Sigma-Aldrich, USA, 1:200 dilution in blocking buffer).

\subsection{Survival Analysis}

One to two-day-old imagoes were placed in test tubes with agar and yeast suspension and were kept at $+25{ }^{\circ} \mathrm{C}$ (30-40 males per vial, with a total of at least 300 males per genotype). Live flies were flipped to a new vial with a fresh medium every 2-3 days and the number of dead individuals was counted. The experiment was conducted until the death of the last fly.

\subsection{Preparation and Analysis of Paraffin Sections}

The total neurodegeneration level was assessed in paraffin brain sections. Flies were fixed for $24 \mathrm{~h}$ in freshly prepared $4 \%$ paraformaldehyde. Then, they were transferred through solutions of $70 \%, 95 \%$, and $100 \%$ ethanol and methyl ester of benzoic acid (Vecton, Russia) and were finally embedded in molten paraffin (Merk, Germany). The obtained fly brain paraffin sections (6- $\mu \mathrm{m}$-thick) were stained with hematoxylin (BioVitrum, Russia) and eosin (BioVitrum, Russia) after deparaffinization. The degree of neurodegeneration was evaluated as the ratio of the total area of vacuoles to an entire area of a brain section (nine flies per genotype and age, with three good-quality sections per fly, resulting in 27 sample values) using a Leica DM 2500 (Leica microsystems, Germany) light microscope and the ImageJ software.

\subsection{Negative Geotaxis Assay}

Locomotor activity and gravity taxis were tested using the RING assay, as described in [33]. Briefly, six groups of 20-40 flies of each genotype and age were transferred into empty vials without anesthesia, and the vials were loaded into the RING apparatus. The apparatus was rapped three times in rapid succession to initiate a negative geotaxis response. The flies' movements in tubes were videotaped and digital images captured $3 \mathrm{~s}$ after initiating the behavior. The distance between a fly and a vial bottom was calculated for each fly. The performance of flies was analyzed in six consecutive trials (interspersed with a $60 \mathrm{~s}$ rest). For each genotype and age, more than 200 flies participated in the experiment, and for each fly, six replicate values were obtained, so the total sample size was more than 1200 values.

\subsection{Learning Indices Assessment}

About 20-30 males per vial were kept until the standard protocol for the olfactory learning test was applied [34,35]. Briefly, all experiments were performed in a temperature- 
controlled dark room using T-maze, with one odorant (3-octanol or 4-methylcyclohexanol (Fluka, Sigma-Aldrich, Germany)) having been compiled with 12 electric stimuli (60 V) for 1 min during training, while the other odorant had not. After a pause of $2 \mathrm{~min}$, flies were allowed to go into two tubes of T-maze, each containing one of the odorants, for $2 \mathrm{~min}$. Finally, the number of flies that stayed in each tube was counted and the half-index was calculated for each vial, as described in [34]. For both tests with octanol and 4-methylcyclohexanol, nine biological replicates were analyzed (i.e., nine vials with 20-30 flies for each of the odorants). Then, we generated 81 independent pairs of learning half-indices, resulting in a sample size of 81 means (learning indices per se). For each age and genotype, more than 600 flies participated in the experiment.

\subsection{Oxidative Particle Measurement}

The reactive oxygen species (ROS) level was measured using $2^{\prime}, 7^{\prime}$-dichlorodihydrofluorescein diacetate (H2DCFDA, Invitrogen, USA), as described in [36]. Twenty heads for each biological replicate among nine total replicates were homogenized in a buffer containing $100 \mu \mathrm{L}$ of $10 \mathrm{mM}$ Tris and $3 \mu \mathrm{L}$ protease inhibitor (Roche, Germany) (pH 7.4). The homogenate was centrifuged (for $10 \mathrm{~min}$ at $10,000 \mathrm{rpm},+4^{\circ} \mathrm{C}$ ). Then, $5 \mu \mathrm{L}$ of clear supernatant was mixed with $60 \mu \mathrm{L}$ of $5 \mu \mathrm{M} \mathrm{H} 2 \mathrm{DCF}-\mathrm{DA}$ and incubated for $60 \mathrm{~min}$ at $+37^{\circ} \mathrm{C}$, and the procedure was repeated three times to obtain three technical replicates for each biological replicate. The fluorescence emission of DCF resulting from DCF-DA oxidation was scanned at $485 \mathrm{~nm}$ excitation and $530 \mathrm{~nm}$ emission with a plate reader (EnSpire2300, PerkinElmer, USA). The values obtained for the ROS levels were normalized to the protein concentration measured by the standard protocol of the Bradford assay and were then averaged for each of the seven biological replicates.

\subsection{Oxidized Glutathione Relative Level Assessment}

To assess the relative level of oxidized glutathione in the brain glia cytoplasm, special sensor stock was used (UAS-cyto-Grx1-roGFP2, kindly donated by Jörg Großhans), as described here [37,38]. Briefly, 12 male brains were incubated in $20 \mu \mathrm{M}$ N-ethyl maleimide (NEM) (Sigma-Aldrich, USA) for $10 \mathrm{~min}$. Then, they were washed in PBS (BioVitrum, Russia), fixed in $4 \%$ formaldehyde solution for $10 \mathrm{~min}$, washed in PBS, and finally placed in Antifade Mounting Medium (Vectashield, Vector Laboratories, USA). The same numbers of brains were preliminarily incubated for $10 \mathrm{~min}$ with $100 \mu \mathrm{M}$ diamide (DA) (Sigma-Aldrich, USA) to oxidize the sensor or $10 \mu \mathrm{M}$ dithiothreitol (DTT) (Sigma-Aldrich, USA) to reduce the sensor and brains were then washed in PBS. All brain samples were analyzed with a Leica LX laser confocal microscope using a $20 \times$ (oil) objective at 405 or $488 \mathrm{~nm}$ excitation and $500-530 \mathrm{~nm}$ emission, resulting in a series of images (total thickness of $100 \mu \mathrm{m}$, and distance between images of $2 \mu \mathrm{m}$ ). A quantitative analysis of the total fluorescence in 3D reconstructed images was performed with ImageJ software (function: total gray area). The criterion for analysis was calculated as the normalized 405/488 ratio of the average fluorescence.

\subsection{Transcriptomic Assay}

Total RNA was extracted from twenty 30-day-old males with the RNeasy Mini Kit (QIAGEN, Germany) with two replicates per genotype, and equal amounts of purified good-quality RNA were then prepared for hybridization using the 3'IVT PLUS Express kit (900720, Affymetrix, Thermo Fisher Scientific, USA), yielding a fragmented biotin-labeled cRNA library. After adding internal probe array controls to the target samples for signal normalization, the mixtures were hybridized with GeneChip Drosophila 2.0 (Affymetrix, Thermo Fisher Scientific, USA), and then washed and stained with a Hybridization, Wash and Stain Kit (900720, Affymetrix, Thermo Fisher Scientific, USA). All procedures were performed according to the manufacturer's protocol. After scanning fluorescent signals from cRNA-chip matrix heteroduplexes, data transformation was conducted with the RMA algorithm and quality control was performed using GeneChip Expression Console Software 
1.4 (Affymetrix, Thermo Fisher Scientific, USA). Eventually, lists of up- and downregulated genes in knockdown flies compared to control flies were obtained, assessing more than 18,500 transcripts with TAC4.0 (Affymetrix, Thermo Fisher Scientific, USA). Functional enrichment analysis of these data files was performed with g:Profiler [39]. For analysis, only the genes with more than a two-fold change in expression (False Discovery Rate $(\mathrm{FDR})<0.05)$ were considered and the gene groups divided by the Gene Ontology (GO) biological process were studied (adjusted $p$-value $<0.05$ ).

\subsection{Results Processing}

Statistical analysis was performed using KyPlot 5.0 software. All samples were tested for normality with the Shapiro-Wilk test. If the distribution was normal, we used parametric tests: The Student t-test for a comparison of two samples and Tukey-Kramer test for multiple comparisons (three or more samples). For normally distributed samples, data were presented as histograms (mean $\pm 95 \%$ confidence interval). For other distribution types, nonparametric tests were used. For a comparison of two samples, the KruskalWallis test was applied, whereas for multiple comparisons (three or more samples), the Steel-Dwass test was performed. For samples where the Shapiro-Wilk test suggested a non-normal distribution, data were presented as box-and-whisker plots. In most cases where there were several technical replicates, we did not average them, but put all the values in one sample, assuming that each value is an independent representative of an entire assembly of a studied parameter (an exception was ROS analysis, described in 2.9).

\section{Results}

\section{1. sws is Expressed in the Central and Peripheral Nervous System in Drosophila Larva and Imago}

Previous studies have shown that the SWS protein is expressed in the interface glia at the neuropil-cortex border, fenestrated and satellite glia in the lamina, medulla neuropile glia at the medulla cortex-neuropil interface, and most of the neurons [10]. Later, it was shown that sws is necessary in SPG and ensheathing glia [11] and its dysfunction leads to neuronal and glial death. It was also initially shown that glial hyperwrapping exists in sws mutants [9]. In our previous work, we found that sws was mainly detected on the surface of the ventral nerve cord, in abdominal nerves, and presynaptically at the neuro-muscular junctions of PNS of the 3rd instar larvae [40].

In this study, we were able to visualize cells with an active sws promoter in the tissues of sws-GAL4;UAS-CD8-GFP 3rd instar larvae and imagoes at the 5th and 30th day of life. We found strong signal in the outer layers of the brain in all examined developmental stages: Plausibly PG and SPG, overlapping with the repo-positive nuclei on the brain surface (Figure $\left.2 \mathrm{~A}-\mathrm{A}^{\prime}, \mathrm{B}-\mathrm{B}^{\prime}, \mathrm{D}-\mathrm{D}^{\prime}\right)$. In addition, there was a weak expression inside the brain and ventral nerve cord (Figure 2A,B). The pictures (Figure 2C,E) show that neuronal nuclei do not overlap with the GFP signal in the brain cortex and ventral nerve cord, suggesting that the sws expression in the neuronal cell bodies and CG is extremely low or absent. In the larval ventral nerve cord, there were several pronounced sws expressing regions corresponding to the metameric structure of thoracic and abdominal ganglia and respective nerves (Figure $2 \mathrm{~A}-\mathrm{A}^{\prime \prime}$ ). 

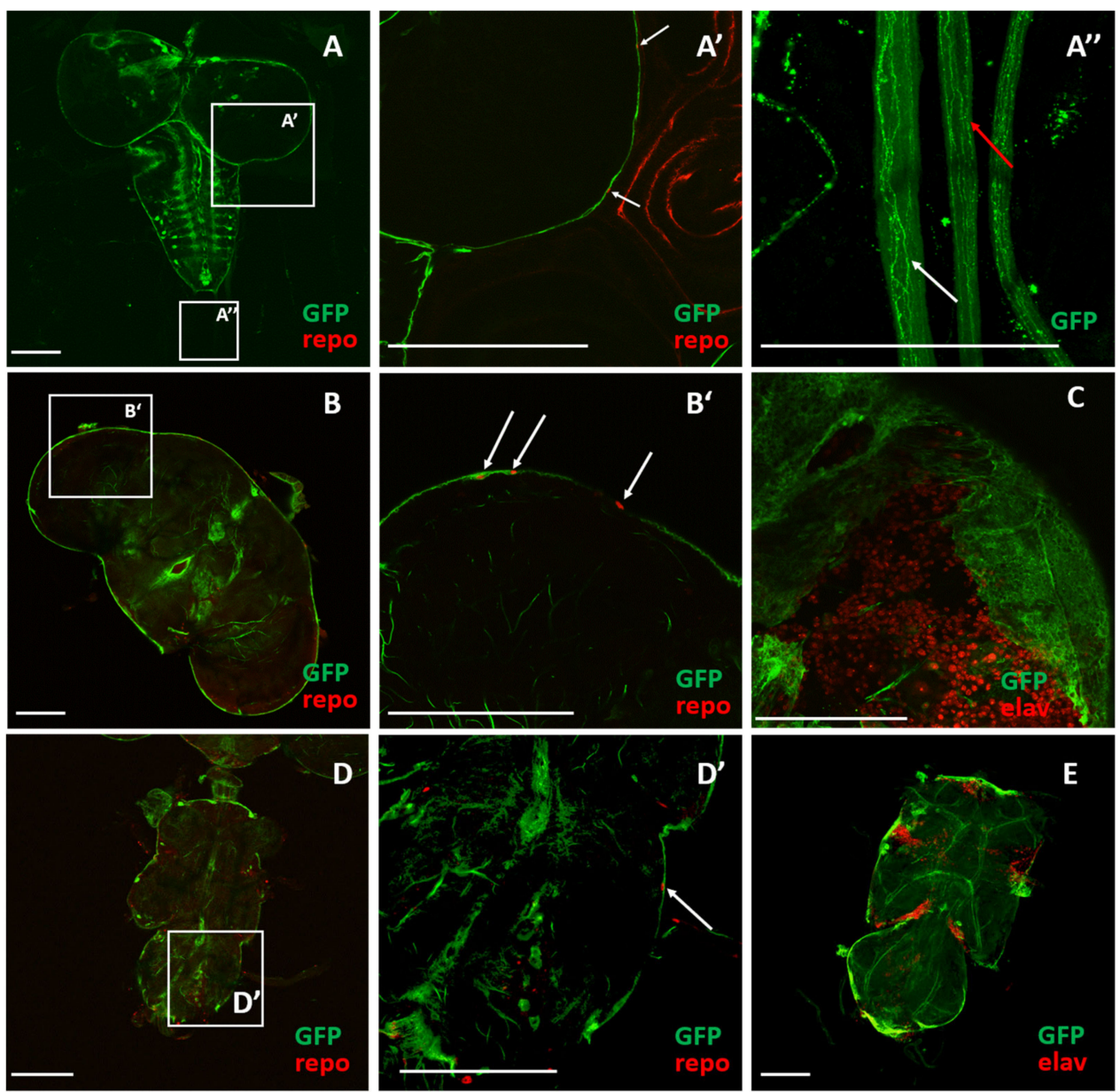

Figure 2. Expression pattern of the sws gene in the Drosophila nervous system. (A-E) Visualization of the sws expression pattern in the transgenic Drosophila melanogaster larval and imago nervous system (sws-GAL4;UAS-CD8-GFP) revealed by confocal microscopy. Scale bar: $100 \mu \mathrm{m}$. Green: GFP embedded in membranes of cells with an active sws promoter. Red: $\left(\mathbf{A}-\mathbf{A}^{\prime}, \mathbf{B}-\mathbf{B}^{\prime}, \mathbf{D}-\mathbf{D}^{\prime}\right)$ glial cell nuclei in the brain and ventral nerve cord, labeled with anti-repo antibodies (marked with white arrows); (C, E) neuronal nuclei labeled with anti-Elav antibodies. (A-A') Brain of 3rd instar larva; (B-B', C) brain of 5-day-old imago; (D-D', E) ventral nerve cord of 5-day-old imago. (A, B, D) Whole view; (A', B', D') magnification; $\left(\mathbf{A}^{\prime \prime}\right)$ abdominal nerves of 3rd instar larva; white arrows show the GFP expression in the abdominal nerves and on their surfaces.

\subsection{The sws Gene is Important for the Structural Maintenance of SPG in CNS}

Since the sws promoter is highly active in the outer layer of the brain and, according to the data on the role of sws in SPG [11], we were curious to know whether the sws gene is important for Drosophila BBB, which is known to be mostly dependent on the SPG function $[15,31,41]$. This type of glia lies between PG and CG and these three types of glia interact with each other [18]. We did not reveal any signal in the cortex of the brain (Figure 2C). We suspected that sws could also be expressed in PG because we revealed signals near the red repo-positive nuclei of different sizes and forms, suggesting that the sws promoter is active in both SPG and PG (Figure 2A-A', B-B'). Moreover, it has not previously been studied whether sws has any functional role in PG, even though it was shown that SWS protein was found in the lamina fenestrated glia (a subtype of PG) [10]. Therefore, we knocked down sws using RNAi and various glia-specific drivers in PG (NPP-GAL4;UASsws-RNAi), SPG (NPS-GAL4;UAS-sws-RNAi), and CG (NPC-GAL4;UAS-sws-RNAi). For the latter, the driver designated as NPC-GAL4 is also expressed in WG $[19,42]$, so it allowed us to analyze the morphology of CG in the CNS and WG in the PNS independently. In order to dissect the role of sws in PG, SPG, and CG, we analyzed the morphology of these glia 
subtypes in KDs at different stages of Drosophila development. We also used additional transgenes to visualize the cell membranes (UAS-CD8-GFP, shown in green, Figure 3) and the nuclei (UAS-RedStinger, shown in red, Figure 3).

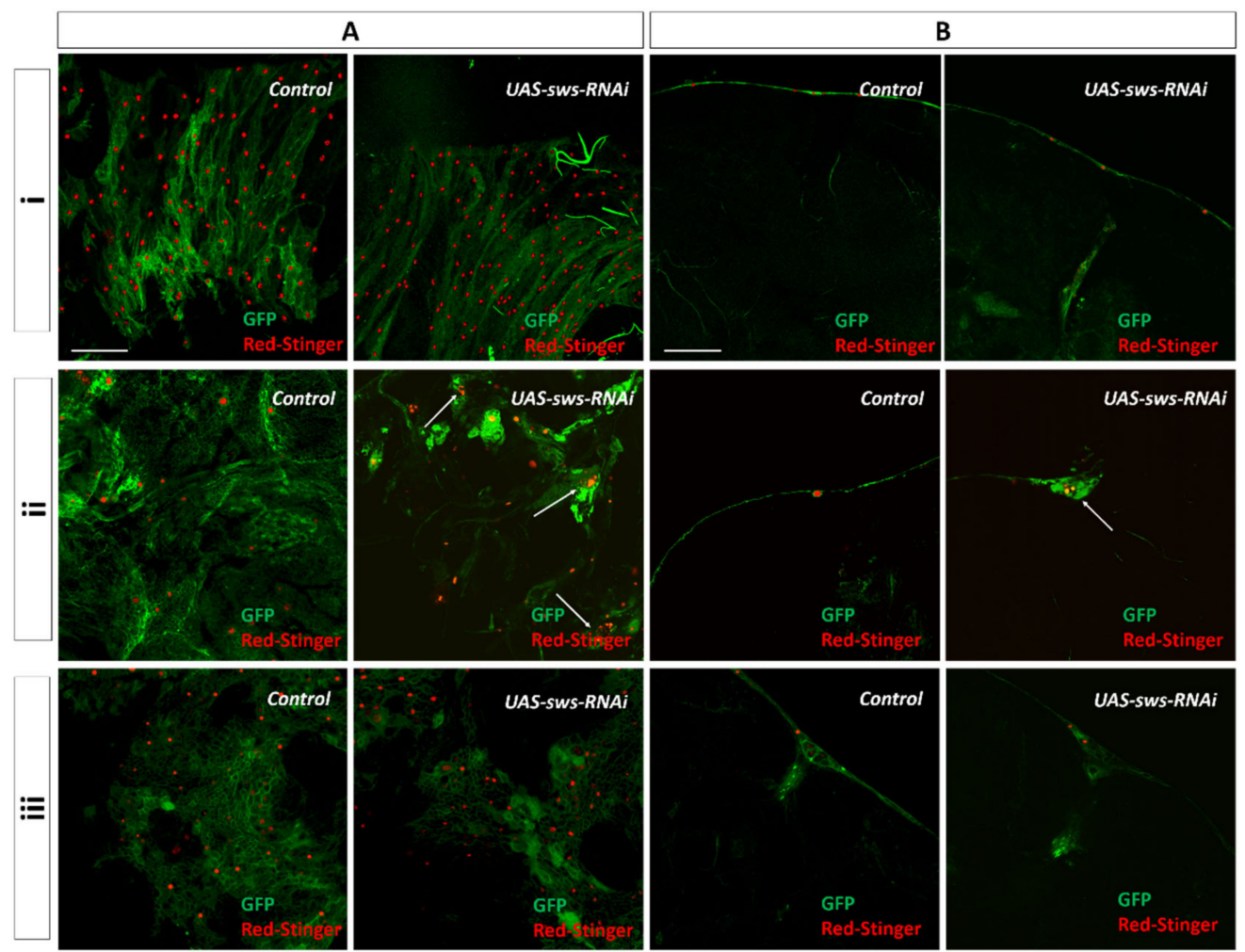

Figure 3. Glia morphology under sws knockdown in the central nervous system (CNS). (A-B) Visualization of glial cells in brains of 30-day-old flies marked with membrane GFP (green, UAS-CD8-GFP) and nuclear red fluorescent protein, RFP (red, UAS-RedStinger) expression in (i) perineurial glia (PG) (NPP-GAL4), (ii) SPG (NPS-GAL4), (iii) cortex glia (CG) (NPC-GAL4) in control and knockdown (KD) (UAS-sws-RNAi) flies. (A) Confocal image of glial cells on the brain surface, and (B) cross-sectional confocal image of the brain. White arrows indicate fragmented glia nuclei. Scale bar: $50 \mu \mathrm{m}$.

Downregulation of sws in PG and CG using the NPP-GAL4 and NPC-GAL4 drivers did not cause the apparent morphological changes.

Additionally, we did not notice any morphological alterations in the larval ganglia under sws KD in SPG. However, in the adult flies, we observed pronounced abnormalities in the SPG layer, which progressed with age. In 5-day-old imago, the SPG layer became discontinuous, gaps were found on the surface of the brain, and the structure of the glia was changed. In 30-day-old animals, the loss of SPG integrity was enhanced: Glial cells on the surface of the brain were grouped together, forming conglomerates with extensive gaps between them (Figure 3iiA,B, arrow; a more detailed structure of SPG is presented in Supplementary Figure S2). In addition, the visualization of DsRed in SPG nuclei shows their fragmentation (Figure 3A, white arrows), which is typical for apoptotic cells [43,44].

\subsection{The sws Gene is Important for the Structural Maintenance of SPG and WG in PNS}

Abdominal nerves, which are part of the PNS, are present in Drosophila melanogaster from the early stages of larval development [45]. In the course of the fly life cycle, abdominal nerves are modified during metamorphosis. Therefore, five posterior nerve pairs (A4-A8) merge to form the terminal nerve [46]. In this work, we analyzed three types of PNS glia (PG, SPG, WG) in the abdominal nerves of 3rd instar larva (nerves A4-A8, Figure 4A-C'), 5-day-old flies (terminal nerve, Figure 4D-F'), and 30-day-old adult flies (terminal nerve, Figure $\left.4 \mathrm{G}-\mathrm{I}^{\prime}\right)$. 


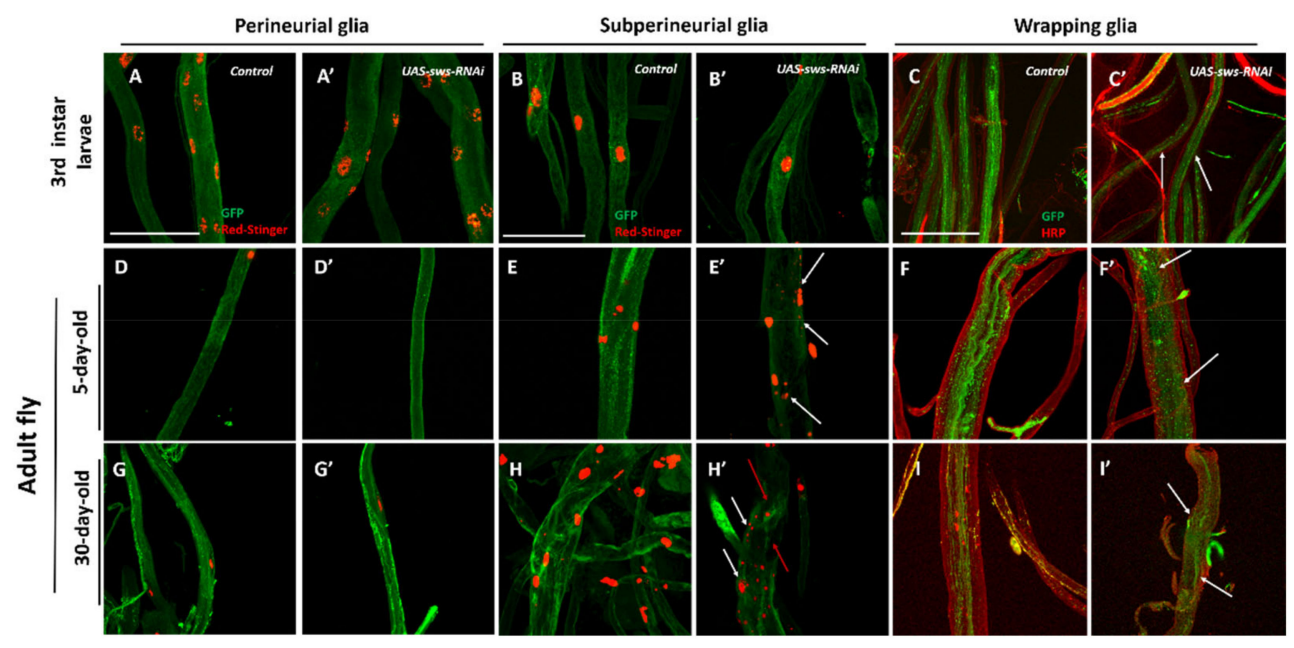

Figure 4. Glia morphology under sws knockdown in PNS. (A-I') Morphology of glial cells in PNS (abdominal proximal

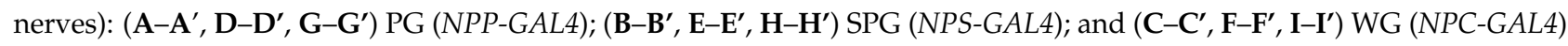
in 3rd instar larvae $\left(\mathbf{A}-\mathbf{A}^{\prime}, \mathbf{B}-\mathbf{B}^{\prime}, \mathbf{C}-\mathbf{C}^{\prime}\right)$, and 5-day-old $\left(\mathbf{D}-\mathbf{D}^{\prime}, \mathbf{E}-\mathbf{E}^{\prime}, \mathbf{F}-\mathbf{F}^{\prime}\right)$ and 30-day-old $\left(\mathbf{G}-\mathbf{G}^{\prime}, \mathbf{H}-\mathbf{H}^{\prime}, \mathbf{I}-\mathbf{I}^{\prime}\right)$ adult flies of control or KD (UAS-sws-RNAi) genotype. Green: GFP in membranes (UAS-CD8-GFP). Red: (A-B', D-E', G-H') RFP expression in nuclei (UAS-RedStinger) or $\left(\mathbf{C}-\mathbf{C}^{\prime}, \mathbf{F}-\mathbf{F}^{\prime}, \mathbf{I}-\mathbf{I}^{\prime}\right)$ red anti-HRP antibody staining of axons. $\left(\mathbf{E}^{\prime}, \mathbf{H}^{\prime}\right)$ White arrows show an increased number of SPG nuclei, and red arrows show a loss of the SPG layer. $\left(\mathbf{C}^{\prime}, \mathbf{F}^{\prime}, \mathbf{I}^{\prime}\right)$ White arrows show a loss of WG. Scale bar: $50 \mu \mathrm{m}$.

We did not find any obvious morphological alterations in the 3rd instar larva abdominal nerves in the case of sws KD in PG or SPG (Figure 4A,B). However, upon sws KD in SPG in 5-day-old imago, the SPG layer of the terminal nerve lost its integrity and this phenotype was enhanced with age. In addition, we observed the fragmentation of SPG nuclei in PNS, similar to what we saw in CNS (Figure $4 \mathrm{E}^{\prime}, \mathrm{H}^{\prime}$, white arrows).

The KD of sws in WG resulted in morphological abnormalities in 3rd instar larva (Figure $4 C-C^{\prime}$, white arrows). This phenotype was also found in 5-day-old imagoes, where WG lost its regular structure (Figure $4 \mathrm{~F}^{\prime}$, white arrows). In 30-day-old imagoes, there was an almost complete loss of the WG layer (Figure $4 \mathrm{I}^{\prime}$, white arrows).

\subsection{Knockdown of sws in Glia Leads to Degeneration in CNS}

The observed morphological phenotypes could be due to the sws-deficit-induced degeneration that was previously described [9-11]. We quantitatively assessed this in two ways: First, we counted the nuclei number of each cell type in the CNS, and second, we measured the total hole area in the brain neuropile.

We found that sws KD had no influence on the number of CG glia nuclei in a fly's brain (Figure 5A1). Moreover, the PG nuclei numbers did not significantly change when sws was downregulated in this cell type (Figure 5A2). In contrast, we observed a severe reduction of the number of SPG glia nuclei, even at the 5th day of the imago's life. This number, however, did not seem to reduce further upon aging (Figure 5A3).

Considering that SPG is the main component of BBB, next, we addressed the question of whether the brain function is affected in flies with SPG sws KD. Through the classical Pavlovian olfactory assay, we were able to assess the Drosophila learning index. We found that sws KD in SPG reduces the index in groups of 5- and 30-day-old flies (Figure 5B). 

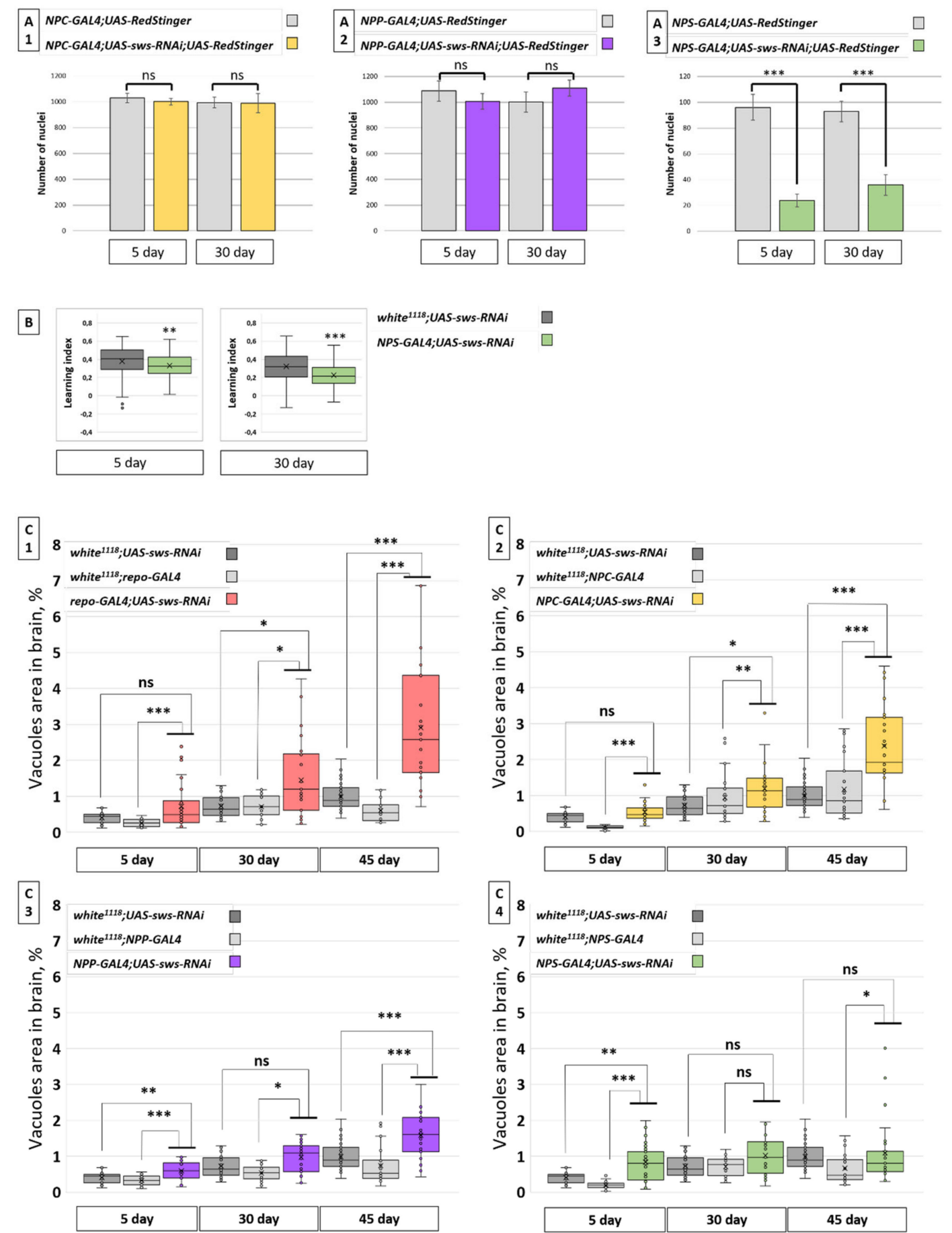

Figure 5. Analysis of degeneration in the fly brains. (A) Number of CG (A1), PG (A2), and SPG (A3) nuclei in fly brains with KD of sws in corresponding glial cells (UAS-sws-RNAi). Student $t$-test, mean $\pm 95 \% \mathrm{CI}, N=25$. (B) The learning index for flies with sws KD in SPG and controls (F1 males from crossing $w^{1118}$ female and UAS-sws-RNAi male, gray boxes). Kruskal-Wallis test, ${ }^{* *} p<0.01,{ }^{* * *} p<0.001, N=91$. (C) Box-and-whisker plots for the total hole area in fly brains with sws KD in all glia types (C1), CG (C2), PG (C3), and SPG (C4). Controls are F1 males obtained from crossing a $w^{1118}$ female and UAS-sws-RNAi male (dark gray boxes) and F1 males obtained from crossing $w^{1118}$ females and one of each of the four GAL4 males used (light gray boxes). Steel-Dwass test, ${ }^{*} p<0.05,{ }^{* *} p<0.01,{ }^{* * *} p<0.001$; ns, no significant difference ( $\left.p>0.05\right)$, $N=27$.

Next, we analyzed the total hole area in fly brains with glia-specific sws KD to assess whether alterations of glia have an impact on CNS axon survival and could potentially 
cause a "swiss cheese" phenotype (Figure 5C) [9]. Firstly, we analyzed the phenotype under panglial sws KD in repo-GAL4;UAS-sws-RNAi flies. We noticed a slight age-dependent increase of the total neuropile degeneration level (Figure 5C1). Surprisingly, a similar pattern was observed in NPC-GAL4;UAS-sws-RNAi (CG sws KD, Figure 5C2) and NPPGAL4;UAS-sws-RNAi (PG sws KD, Figure 5C3) flies. A quite different picture was revealed for SPG sws KD: There was only an increase in the vacuole area compared to controls in 5-day-old flies. These data demonstrate that the analyzed brain degeneration index only slightly increased in flies with sws KD in the examined glia types. Therefore, we propose that the downregulation of sws expression in glia is not critical for whole brain integrity and neuronal survival (Supplementary Table S1).

\subsection{Glial Knockdown of sws is Associated with Impaired Behavior}

To assess the functional consequences of the morphological alterations observed, we analyzed some common neurobiological traits, namely, the organism survival (lifespan) and behavior. The lifespan is often used as a combined biological measure of the functional state of flies [47]. We did not reveal any lifespan reduction in any of the four glia-specific sws KDs, suggesting that sws expression decline in glia is not fatal for flies (Supplementary Figure S3).

It was previously shown that, in a fast phototaxis assay, the locomotion activity of flies with the Gli-GAL4;sws GD3277 genotype is reduced, where sws is knocked down in SPG [21]. When trying to find out whether the morphological defects observed have behavioral consequences, we analyzed locomotor activity in a negative geotaxis test (Figure 6). We found that in all four sws KDs, the locomotor index was reduced in 30- and 45-day-old flies, suggesting that sws is important in PG, SPG, and CG + WG for locomotor performance. Moreover, in SPG glia sws KD, as well as in panglial sws KD, the index was lower compared to controls, even in 5-day-old flies, which is in accordance with our morphology and neurodegeneration data for these genotypes.

\subsection{Whole-Organism Transcriptome Analysis of Flies with sws KD}

Being a regulatory subunit of protein kinase A $[7,8]$, the SWS protein can influence the gene expression profile, thus making it possible to reveal the changes at the transcriptomic level in response to changes in sws expression levels. Moreover, the impairment of functions that are under the control of the sws gene can lead to intracellular physiology fluctuations and intercellular communication deviations; therefore, having an influence not only on cells with sws KD, but also on the whole organism (or at least on the nervous tissue that in its turn is an orchestrator of multiple processes). In addition, the observed morphology phenotypes may induce some other organism reactions, such as inflammation. Taking these statements into account, we tried to assess the organism response to sws KD in SPG and CG + WG. Therefore, whole-fly transcriptome analysis was performed. We studied changes of transcript levels in adult 30-day-old SPG and CG + WG sws KDs compared to CantonS control flies. In the case of SPG sws KD, we found 856 genes to be upregulated. These genes control the organism and cell response to infection, immunity, proteolysis, and metabolism of carboxylic acids and glutathione (Supplementary Figures S4 and S5). Among the 541 genes that were downregulated, functional enrichment analysis revealed reproductive processes and protein metabolism to be overrepresented (Supplementary Figures S6 and S7). As for CG + WG sws KD, we showed 1026 upregulated genes. They control the metabolism of various molecules, including carboxylic acids, lipids, amino acids, carbohydrates, xenobiotics, flavonoids, glucuronate, and glutathione (Supplementary Figures S8 and S9). Among the 691 downregulated genes, there were several statistically significant overrepresented processes regulating organism reproduction (Supplementary Figure S10 and S11). 

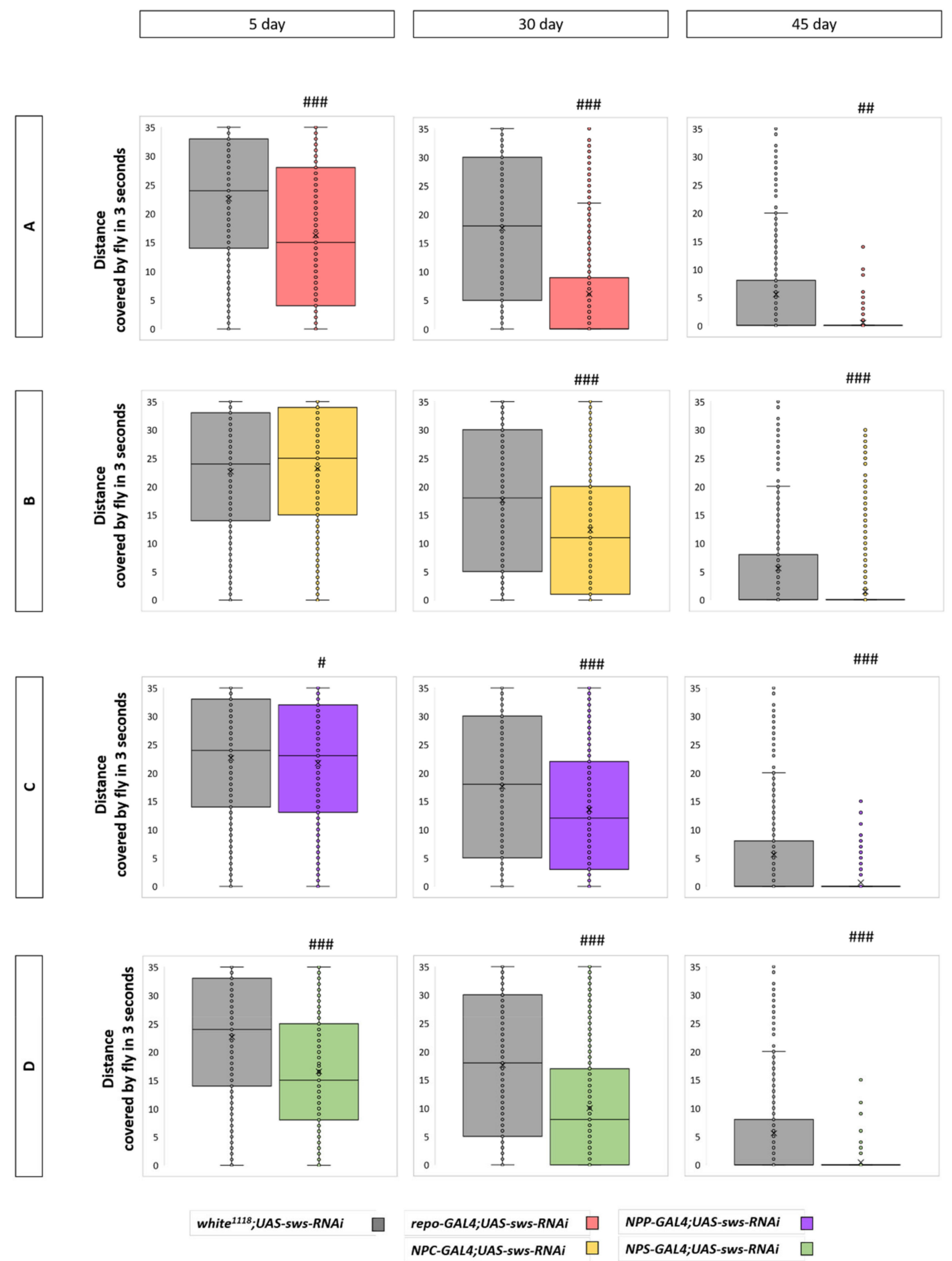

Figure 6. Locomotor activity analysis. (A-D) Distance covered by flies for $3 \mathrm{~s}$ after flipping in the RING assay for flies with sws KD in all types of glia (A), CG + WG (B), PG (C), SPG (D), and controls (F1 males obtained from crossing a $w^{1118}$ female and UAS-sws-RNAi male) at different ages. Kruskal-Wallis test, $\# p<0.05, \# \#<<0.01, \# \# p<0.001, N>1200$.

\subsection{Glial Knockdown of sws is Associated with Increased ROS Levels}

It is known that neurodegenerative phenotypes are often accompanied by ROS acceleration [48]. Therefore, we performed brain ROS level analysis using an H2DCF-DA probe in whole-head lysates (Figure 7A-D). We found slight ROS acceleration in all glia sws KD flies (repo-GAL4;UAS-sws-RNAi) and in SPG sws KD flies at 5, 30, and 45 days of life. Additionally, there was ROS increase in 5- and 30-day-old CG sws KD. To confirm that 
the observed ROS acceleration is induced by sws downregulation, we performed a rescue experiment. For this, we expressed a human sws orthologue-NTE-in a repo-GAL4;UASsws-RNAi background, revealing ROS level reduction to normal values (at the 5th day of life) or even less than the control level (at the 30th day of life, Figure 5E). Having revealed that under SPG and CG + WG sws KD, glutathione metabolism genes are upregulated, we decided to analyze whether the observed ROS acceleration is at least partially utilized by the glutathione antioxidant system. Therefore, we analyzed the relative oxidized glutathione level in brains of panglial sws KD (repo-GAL4;UAS-sws-RNAi) flies and found an elevation of it compared to the control (Figure 7F).
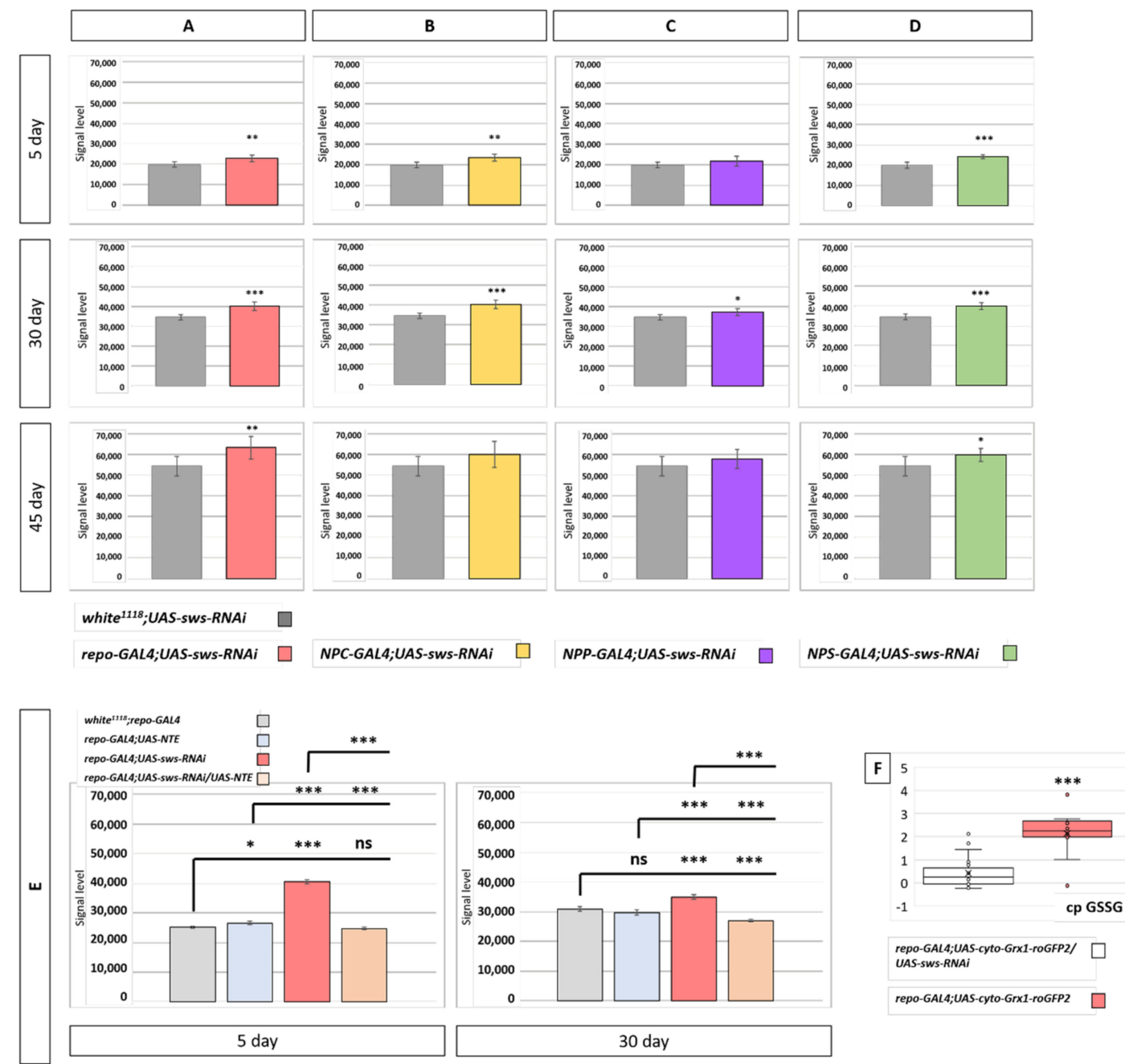

Figure 7. Reactive oxygen species analysis. (A-D) Fluorescent signal level corresponding to the total reactive oxygen species (ROS) concentration in brain samples of flies with sws KD in all glia (A), CG (B), PG (C), SPG (D), and controls (F1 males obtained from crossing a $w^{1118}$ female and UAS-sws-RNAi male) at different ages. Student $t$-test, mean $\pm 95 \% \mathrm{CI}$ is shown, $N=7$. (E) Fluorescent signal level corresponding to the total ROS concentration in brain samples of repo-GAL4 flies with human NTE overexpression (UAS-NTE), sws KD in all types of glia (UAS-sws-RNAi), and rescue of sws loss (UAS-NTE/UAS-sws-RNAi). Controls are F1 males from crossing a $w^{1118}$ female and repo-GAL4 male. Tukey-Kramer test, mean $\pm 95 \% \mathrm{CI}$ is shown. ${ }^{*} p<0.05 ;{ }^{* *} p<0.01 ;{ }^{* *} p<0.001$; ns, no significant difference $(p>0.05) \mathrm{N}=7$. ( F) Relative level of oxidized glutathione in the glia cytoplasm of panglial sws KD (repo-GAL4;UAS-cyto-Grx1-roGFP2/UAS-sws-RNAi, red box) and controls (repo-GAL4;UAS-cyto-Grx1-roGFP2, gray box) at the 30th day of life. Kruskal-Wallis test, ${ }^{* * *} p<0.001, N=12$. OY axis, relative ratio of sensor fluorescence. 


\section{Discussion}

Glial cells are known to be essential elements of the nervous system that are critical for the development and maintenance of neurons, including their protection from changing environments [49-53]. Drosophila melanogaster is a great model for investigating developmental, morphological, and functional aspects of glia biology [18,54-56]. Among multiple neuron-glia interactions, one of the most vital is hemolymph-neuron protective isolation performed by glia in the fruit fly $[13,57,58]$. Recent studies have identified numerous genes that are associated with specific glia functioning in Drosophila [21,29-31]. Here, we show that the sws gene is important for glia maintenance in Drosophila melanogaster. We found that sws is expressed not only in imago's neuropil, but also in brain surface and nerves (where BBB/BNB glia are located) at the larval stage of development (when BBB/BNB glia grow [59]), as well as at the imago stage. Therefore, we propose that the sws function is important for, at least, the late development and maintenance of BBB/BNB glia.

We identified that both SPG and WG require a normal sws expression for structural stability. The former glia type is known to be a major constituent of insect BBB/BNB [15,16]. The latter type of glia serves as non-myelinating cells that ensheath axons in peripheral nerves to provide both proper conductance and nerve integrity $[15,28]$. We suppose that the observed glia impairment may be associated with the sws function. It has been welldemonstrated that lipid metabolism in glia is crucial for stress reaction under different conditions, primarily associated with oxidative stress [60-62]. Being a phospholipase [10], SWS plays an important role, not only for lipid metabolism, but also for stress regulation, thus providing cell metabolism and survival [63]. This could explain why the downregulation of sws in the case of KD results in ROS elevation in the brain, suggesting that a loss of the glia defense function occurs.

To check whether this hypothesis is true, we applied RNA-interference-induced KD of sws in those cell types that could influence Drosophila BBB and BNB. Among the studied glia types, it was shown that only SPG demands sws expression for a normal brain condition. The KD of sws in SPG led to membranous structures and vacuole formation in the lamina cortex [11]. However, the SPG-specific function of sws was not shown. We demonstrated that a lack of sws expression in SPG disrupted the layer of these cells in 5-day-old flies and the SPG nuclei number was reduced. This phenotype progressed to the 30th day of adult life. In addition, not only the structure of the cell layer, but also numerous fragmented nuclei, accumulated in residual SPG "islets" and were typical for apoptotic cells [43,44]. These abnormalities were observed in both CNS and PNS. The phenotype was accompanied by a locomotor activity decline in the negative geotaxis test, supporting previous data about defects in a fast phototaxis assay for Gli-GAL4;sws ${ }^{G D 3277}$ flies (another variant of SPG sws KD) [11]. It was demonstrated that in case of human neurodegenerative disorders with even mild memory disturbances, BBB leaking occurs [64-66]. Hence, proposing an alteration of BBB integrity in our flies, we analyzed the cognitive function of SPG sws KDs. We found a learning (a.k.a. immediate memory) deficit in examined flies. The general morphological state of the brain seemed to be normal, even though there was a slight neuropile degeneration index increase. However, the brain ROS level was accelerated in SPG sws KD flies, suggesting that the brain function was altered under an induced condition. Despite the observed pathological phenotypes, the longevity of KD flies did not change. Nevertheless, these data suggest that the main cell type of BBB-SPG-demands a normal sws expression for maintenance and function. The KD of sws in SPG leads to dramatic morphological alterations, oxidative stress, and behavior deficits.

As for PG sws KD, we did not find any morphological abnormalities. However, we found a few more vacuoles in the brains of these flies; however, we still propose that this could be part of normal variation because of the small effect size. The small increase of the brain ROS level in 30-day-old KD had quite low statistical significance $(p=0.018)$. However, we found a locomotor activity decline at day 30 and 45 . Therefore, the potential role of sws in PG cells has to be studied in more detail. On the one hand, we were not able to show whether the sws promoter is active in both PG and SPG layers, or only in one of them. On 
the other hand, there is no doubt that sws is necessary, at least in SPG. Our data suggest that the locomotor activity decline observed in PG sws KD could be an argument to further investigate the role of sws in this glia subtype.

We observed no visible activity of the sws promoter in CG. Additionally, we found no morphology and nuclei number changes under CG sws KD. Surprisingly, there was increased vacuole formation in the brain neuropile and an accelerated ROS level. This was accompanied by a locomotor activity decline. While the brain phenotype is puzzling for us, the locomotor phenotype could be associated with WG, because we used the same driver for both cell types (NPC-GAL4). In WG, we found morphological abnormalities in 3 rd instar larvae, and the phenotype progressed in imago, resulting in the complete loss of WG in peripheral nerves to the 30th day.

To assess organism changes under SPG or CG + WG sws KD in 30-day-old imagoes, we analyzed the transcriptome of whole flies. This let us roughly analyze general changes in organisms compared to the control with normal sws expression (CantonS). Hundreds of genes were up- or downregulated under the KD condition. In the case of SPG sws $K D$, there were genes controlling the immunity and defense reaction. This could indicate consequences of BBB impairment. As for CG + WG sws KD, there were various genes controlling metabolism. Considering the fact that these two types of glia are tightly associated with neurons and supply them with nutrients, KD could alter respective neuronglia interactions. We found that in both SPG and CG + WG sws KDs, glutathione metabolism genes were upregulated. Glutathione is known to be the major natural endogenous antioxidant in a wide variety of species, including fruit flies. We therefore performed an analysis of the relative oxidized glutathione level in glia and revealed an elevation of this parameter in 30-day-old fly brains with panglial sws KD. This confirms our results about ROS acceleration in fly brains of several genotypes. In addition, organism reproduction genes were downregulated in both KDs. This could be due to an organism stress reaction, which implies activation of the defense response and organism survival.

It was previously documented that sws dysfunction results in neuronal and glial cell death [9-11]. This leads to locomotor deficits due to both neuronal and glial dysfunction. For instance, neuromuscular junction alterations are accompanied with by an active zone decline and postsynaptic reaction to this deterioration due to the neuronal sws KD in Drosophila [40]. The human sws orthologue is associated with several syndromes of the spasticity - ataxia continuum caused by neurodegeneration in the spinal cord, cerebellum, and/or pituitary gland [67]. The murine sws orthologue is necessary for non-myelinating Schwann cells to ensheath axons in Remak fibers [68]. In the fruit fly, a similar function is performed by WG, which we demonstrated to be dependent on sws for peripheral nerve structural maintenance and locomotor activity. Furthermore, SPG glia could not properly ensheath ganglia and nerves under sws KD. Being normal in larvae, they are severely disrupted in young imagoes. Although we did not directly show that the two mentioned cell types die in the case of sws KD, the gene is crucial in these cells not only for proper morphology maintenance, but also for the normal functional state of the organism.

\section{Conclusions}

Taken together, we have shown that normal sws expression is important for the regular structure of SPG in adults and WG in both 3rd instar larvae and adults. Under sws KD, these cell types are responsible for the locomotor activity decline. Moreover, the SPG KD phenotype is associated with an elevated ROS level in the brain and learning deficiency. However, the mechanisms of neurodegeneration under sws knockdown, as well as an evidence for the role of sws in PG and CG, remain unknown.

Supplementary Materials: The following are available online at https://www.mdpi.com/2073 -4409/10/3/529/s1: Supplementary Table S1. Neuropile degeneration index (total vacuole area in the brain neuropile) in flies with different genotypes and three ages; Supplementary Figure S1. Automated analysis of the SPG nuclei in ImageJ; Supplementary Figure S2. Subperineurial glia morphology under sws knockdown in the CNS; Supplementary Figure S3. Longevity assay; 
Supplementary Figure S4. Processes under the control of upregulated genes in 30-day-old SPG sws KD males compared to CantonS control and respective FDR-adjusted p-values of functional enrichment analysis in g:Profiler software; Supplementary Figure S5. Processes under the control of upregulated genes in 30-day-old SPG sws KD males compared to CantonS control and respective query gene number from functional enrichment analysis in g:Profiler software; Supplementary Figure S6. Processes under the control of downregulated genes in 30-day-old SPG sws KD males compared to CantonS control and respective FDR-adjusted p-values of functional enrichment analysis in g:Profiler software; Supplementary Figure S7. Processes under the control of downregulated genes in 30-day-old SPG sws KD males compared to CantonS control and respective query gene number from functional enrichment analysis in g:Profiler software; Supplementary Figure S8. Processes under the control of upregulated genes in 30-day-old CG + WG sws KD males compared to CantonS control and respective FDR-adjusted p-values of functional enrichment analysis in g:Profiler software; Supplementary Figure S9. Processes under the control of upregulated genes in 30-day-old CG + WG sws KD males compared to CantonS control and the respective query gene number from functional enrichment analysis in g:Profiler software; Supplementary Figure S10. Processes under the control of downregulated genes in 30-day-old CG + WG sws KD males compared to CantonS control and respective FDR-adjusted p-values of functional enrichment analysis in g:Profiler software; Supplementary Figure S11. Processes under the control of downregulated genes in 30-day-old CG + WG sws KD males compared to CantonS control and the respective query gene number from functional enrichment analysis in g:Profiler software.

Author Contributions: Conceptualization, E.V.R., and S.V.S.; methodology and validation, E.V.R., P.A.M., A.E.K., N.V.S. E.A.I., and S.V.S.; formal analysis, E.V.R., P.A.M., A.E.K., N.V.S., E.A.I., and S.V.S.; investigation, E.V.R., P.A.M., A.E.K., N.V.S., E.A.I., and S.V.S.; writing-original draft preparation, E.V.R., P.A.M., and S.V.S.; writing-review and editing, N.M., H.R.S., and S.V.S.; funding acquisition, H.R.S. and S.V.S. All authors have read and agreed to the published version of the manuscript.

Funding: The reported study was funded by RFBR (project number 19-34-90151), and Volkswagen Stiftung (grants 90218 and 97750).

Institutional Review Board Statement: The study was conducted according to the guidelines of the Declaration of Helsinki, and approved by the Ethical Committee of the Petersburg Nuclear Physics Institute named by B.P. Konstantinov of NRC «Kurchatov Institute» (protocol \# 01/КПБо 13 January 2020).

Informed Consent Statement: Not applicable.

Data Availability Statement: The data presented in this study are available in the article and Supplementary Materials.

Acknowledgments: We thank Svetlana Timoshenko for the preparation of paraffin sections. We also thank Jörg Großhans and Robert Wessells for providing us with Drosophila strains and Andriy Yatsenko for comments on the manuscript.

Conflicts of Interest: The authors declare no conflict of interest.

\section{References}

1. Moser, M.; Stempfl, T.; Li, Y.; Glynn, P.; Büttner, R.; Kretzschmar, D. Cloning and Expression of the Murine Sws/NTE Gene. Mech. Dev. 2000, 90, 279-282. [CrossRef]

2. Johnson, M.K. The Delayed Neurotoxic Effect of Some Organophosphorus Compounds. Identification of the Phosphorylation Site as an Esterase. Biochem. J. 1969, 114, 711-717. [CrossRef]

3. Rainier, S.; Bui, M.; Mark, E.; Thomas, D.; Tokarz, D.; Ming, L.; Delaney, C.; Richardson, R.J.; Albers, J.W.; Matsunami, N.; et al. Neuropathy Target Esterase Gene Mutations Cause Motor Neuron Disease. Am. J. Hum. Genet. 2008, 82, 780-785. [CrossRef]

4. Deik, A.; Johannes, B.; Rucker, J.C.; Sánchez, E.; Brodie, S.E.; Deegan, E.; Landy, K.; Kajiwara, Y.; Scelsa, S.; Saunders-Pullman, R.; et al. Compound Heterozygous PNPLA6 Mutations Cause Boucher-Neuhäuser Syndrome with Late-Onset Ataxia. J. Neurol 2014, 261, 2411-2423. [CrossRef]

5. Synofzik, M.; Gonzalez, M.A.; Lourenco, C.M.; Coutelier, M.; Haack, T.B.; Rebelo, A.; Hannequin, D.; Strom, T.M.; Prokisch, H.; Kernstock, C.; et al. PNPLA6 Mutations Cause Boucher-Neuhäuser and Gordon Holmes Syndromes as Part of a Broad Neurodegenerative Spectrum. Brain 2014, 137, 69-77. [CrossRef] 
6. Zaccheo, O.; Dinsdale, D.; Meacock, P.A.; Glynn, P. Neuropathy Target Esterase and Its Yeast Homologue Degrade Phosphatidylcholine to Glycerophosphocholine in Living Cells*. J. Biol. Chem. 2004, 279, 24024-24033. [CrossRef] [PubMed]

7. Da Cruz, A.B.; Wentzell, J.; Kretzschmar, D. Swiss Cheese, a Protein Involved in Progressive Neurodegeneration, Acts as a Noncanonical Regulatory Subunit for PKA-C3. J. Neurosci. 2008, 28, 10885-10892. [CrossRef] [PubMed]

8. Wentzell, J.S.; Cassar, M.; Kretzschmar, D. Organophosphate-Induced Changes in the PKA Regulatory Function of Swiss Cheese/NTE Lead to Behavioral Deficits and Neurodegeneration. Plos One 2014, 9, e87526. [CrossRef] [PubMed]

9. Kretzschmar, D.; Hasan, G.; Sharma, S.; Heisenberg, M.; Benzer, S. The Swiss Cheese Mutant Causes Glial Hyperwrapping and Brain Degeneration in Drosophila. J. Neurosci. 1997, 17, 7425-7432. [CrossRef] [PubMed]

10. Mühlig-Versen, M.; Cruz, A.B. da; Tschäpe, J.-A.; Moser, M.; Büttner, R.; Athenstaedt, K.; Glynn, P.; Kretzschmar, D. Loss of Swiss Cheese/Neuropathy Target Esterase Activity Causes Disruption of Phosphatidylcholine Homeostasis and Neuronal and Glial Death in Adult Drosophila. J. Neurosci. 2005, 25, 2865-2873. [CrossRef]

11. Dutta, S.; Rieche, F.; Eckl, N.; Duch, C.; Kretzschmar, D. Glial Expression of Swiss Cheese (SWS), the Drosophila Orthologue of Neuropathy Target Esterase (NTE), Is Required for Neuronal Ensheathment and Function. Dis. Models Mech. 2016, 9, 283-294. [CrossRef]

12. Carlson, S.D.; Juang, J.-L.; Hilgers, S.L.; Garment, M.B. Blood Barriers of the Insect. Annu. Rev. Entomol. 2000, 45, 151-174. [CrossRef]

13. Daneman, R.; Barres, B.A. The Blood-Brain Barrier- Lessons from Moody Flies. Cell 2005, 123, 9-12. [CrossRef] [PubMed]

14. Abbott, N.J.; Rönnbäck, L.; Hansson, E. Astrocyte-Endothelial Interactions at the Blood-Brain Barrier. Nat. Rev. Neurosci. 2006, 7, 41-53. [CrossRef]

15. Stork, T.; Engelen, D.; Krudewig, A.; Silies, M.; Bainton, R.J.; Klämbt, C. Organization and Function of the Blood-Brain Barrier in Drosophila. J. Neurosci. 2008, 28, 587-597. [CrossRef]

16. Desalvo, M.K.; Mayer, N.; Mayer, F.; Bainton, R.J. Physiologic and Anatomic Characterization of the Brain Surface Glia Barrier of Drosophila. Glia 2011, 59, 1322-1340. [CrossRef]

17. DeSalvo, M.K.; Hindle, S.J.; Rusan, Z.M.; Orng, S.; Eddison, M.; Halliwill, K.; Bainton, R.J. The Drosophila Surface Glia Transcriptome: Evolutionary Conserved Blood-Brain Barrier Processes. Front. Neurosci. 2014, 8. [CrossRef]

18. Kremer, M.C.; Jung, C.; Batelli, S.; Rubin, G.M.; Gaul, U. The Glia of the Adult Drosophila Nervous System: Glia Anatomy in Adult Drosophila Nervous System. Glia 2017, 65, 606-638. [CrossRef]

19. Awasaki, T.; Lai, S.-L.; Ito, K.; Lee, T. Organization and Postembryonic Development of Glial Cells in the Adult Central Brain of Drosophila. J. Neurosci. 2008, 28, 13742-13753. [CrossRef] [PubMed]

20. Unhavaithaya, Y.; Orr-Weaver, T.L. Polyploidization of Glia in Neural Development Links Tissue Growth to Blood-Brain Barrier Integrity. Genes Dev. 2012, 26, 31-36. [CrossRef]

21. Zülbahar, S.; Sieglitz, F.; Kottmeier, R.; Altenhein, B.; Rumpf, S.; Klämbt, C. Differential Expression of Öbek Controls Ploidy in the Drosophila Blood-Brain Barrier. Development 2018, 145, dev164111. [CrossRef] [PubMed]

22. Juang, J.-L.; Carlson, S.D. A Blood-Brain Barrier without Tight Junctions in the Fly Central Nervous System in the Early Postembryonic Stage. Cell Tissue Res. 1992, 270, 95-103. [CrossRef]

23. Baumgartner, S.; Littleton, J.T.; Broadie, K.; Bhat, M.A.; Harbecke, R.; Lengyel, J.A.; Chiquet-Ehrismann, R.; Prokop, A.; Bellen, H.J. A Drosophila Neurexin Is Required for Septate Junction and Blood-Nerve Barrier Formation and Function. Cell 1996, 87, 1059-1068. [CrossRef]

24. Bhat, M.A.; Rios, J.C.; Lu, Y.; Garcia-Fresco, G.P.; Ching, W.; Martin, M.St.; Li, J.; Einheber, S.; Chesler, M.; Rosenbluth, J.; et al. Axon-Glia Interactions and the Domain Organization of Myelinated Axons Requires Neurexin IV/Caspr/Paranodin. Neuron 2001, 30, 369-383. [CrossRef]

25. Banerjee, S.; Pillai, A.M.; Paik, R.; Li, J.; Bhat, M.A. Axonal Ensheathment and Septate Junction Formation in the Peripheral Nervous System of Drosophila. J. Neurosci. 2006, 26, 3319-3329. [CrossRef]

26. Kis, V.; Barti, B.; Lippai, M.; Sass, M. Specialized Cortex Glial Cells Accumulate Lipid Droplets in Drosophila Melanogaster. PLoS ONE 2015, 10, e0131250. [CrossRef] [PubMed]

27. Von Hilchen, C.M.; Beckervordersandforth, R.M.; Rickert, C.; Technau, G.M.; Altenhein, B. Identity, Origin, and Migration of Peripheral Glial Cells in the Drosophila Embryo. Mech. Dev. 2008, 125, 337-352. [CrossRef] [PubMed]

28. Kottmeier, R.; Bittern, J.; Schoofs, A.; Scheiwe, F.; Matzat, T.; Pankratz, M.; Klämbt, C. Wrapping Glia Regulates Neuronal Signaling Speed and Precision in the Peripheral Nervous System of Drosophila. Nat. Commun. 2020, 11, 4491. [CrossRef]

29. Matzat, T.; Sieglitz, F.; Kottmeier, R.; Babatz, F.; Engelen, D.; Klämbt, C. Axonal Wrapping in the Drosophila PNS Is Controlled by Glia-Derived Neuregulin Homolog Vein. Development 2015, 142, 1336-1345. [CrossRef]

30. Kanda, H.; Shimamura, R.; Koizumi-Kitajima, M.; Okano, H. Degradation of Extracellular Matrix by Matrix Metalloproteinase 2 Is Essential for the Establishment of the Blood-Brain Barrier in Drosophila. iScience 2019, 16, 218-229. [CrossRef]

31. Bainton, R.J.; Tsai, L.T.-Y.; Schwabe, T.; DeSalvo, M.; Gaul, U.; Heberlein, U. Moody Encodes Two GPCRs That Regulate Cocaine Behaviors and Blood-Brain Barrier Permeability in Drosophila. Cell 2005, 123, 145-156. [CrossRef] [PubMed]

32. Kretzschmar, D. Swiss Cheese et Allii, Some of the First Neurodegenerative Mutants Isolated in Drosophila. J. Neurogenet. 2009, 23, 34-41. [CrossRef]

33. Gargano, J.W.; Martin, I.; Bhandari, P.; Grotewiel, M.S. Rapid Iterative Negative Geotaxis (RING): A New Method for Assessing Age-Related Locomotor Decline in Drosophila. Exp. Gerontol. 2005, 40, 386-395. [CrossRef] 
34. Quinn, W.G.; Harris, W.A.; Benzer, S. Conditioned Behavior in Drosophila Melanogaster. PNAS 1974, 71, 708-712. [CrossRef] [PubMed]

35. Tully, T.; Quinn, W.G. Classical Conditioning and Retention in Normal and MutantDrosophila Melanogaster. J. Comp. Physiol. 1985, 157, 263-277. [CrossRef]

36. Pérez-Severiano, F.; Rodríguez-Pérez, M.; Pedraza-Chaverrí, J.; Maldonado, P.D.; Medina-Campos, O.N.; Ortíz-Plata, A.; SánchezGarcía, A.; Villeda-Hernández, J.; Galván-Arzate, S.; Aguilera, P.; et al. S-Allylcysteine, a Garlic-Derived Antioxidant, Ameliorates Quinolinic Acid-Induced Neurotoxicity and Oxidative Damage in Rats. Neurochem. Int. 2004, 45, 1175-1183. [CrossRef]

37. Albrecht, S.C.; Barata, A.G.; Großhans, J.; Teleman, A.A.; Dick, T.P. In Vivo Mapping of Hydrogen Peroxide and Oxidized Glutathione Reveals Chemical and Regional Specificity of Redox Homeostasis. Cell Metab. 2011, 14, 819-829. [CrossRef]

38. Barata, A.G.; Dick, T.P. Chapter Four - In Vivo Imaging of H2O2 Production in Drosophila. Methods in Enzymol. 2013, 526, 61-82.

39. Reimand, J.; Isserlin, R.; Voisin, V.; Kucera, M.; Tannus-Lopes, C.; Rostamianfar, A.; Wadi, L.; Meyer, M.; Wong, J.; Xu, C.; et al. Pathway Enrichment Analysis and Visualization of Omics Data Using g:Profiler, GSEA, Cytoscape and EnrichmentMap. Nat. Protoc. 2019, 14, 482-517. [CrossRef] [PubMed]

40. Ryabova, E.; Matiytsiv, N.; Trush, O.; Mohylyak, I.; Kislik, G.; Melentev, P.; Sarantseva, S. Swiss Cheese, Drosophila Ortholog of Hereditary Spastic Paraplegia Gene NTE, Maintains Neuromuscular Junction Development and Microtubule Network. In Drosophila melanogaster-Model for Recent Advances in Genetics and Therapeutics; Perveen, F.K., Ed.; IntechOpen: London, UK, 2018. [CrossRef]

41. Schwabe, T.; Bainton, R.J.; Fetter, R.D.; Heberlein, U.; Gaul, U. GPCR Signaling Is Required for Blood-Brain Barrier Formation in Drosophila. Cell 2005, 123, 133-144. [CrossRef] [PubMed]

42. Coutinho-Budd, J.C.; Sheehan, A.E.; Freeman, M.R. The Secreted Neurotrophin Spätzle 3 Promotes Glial Morphogenesis and Supports Neuronal Survival and Function. Genes Dev. 2017, 31, 2023-2038. [CrossRef] [PubMed]

43. Khwaja, F.S.; Quann, E.J.; Pattabiraman, N.; Wynne, S.; Djakiew, D. Carprofen Induction of P75NTR-Dependent Apoptosis via the P38 Mitogen-Activated Protein Kinase Pathway in Prostate Cancer Cells. Mol Cancer 2008, 7, 3539-3545. [CrossRef]

44. Nhiem, N.X.; Thu, V.K.; Van Kiem, P.; Van Minh, C.; Tai, B.H.; Quang, T.H.; Cuong, N.X.; Yen, P.H.; Boo, H.-J.; Kang, J.-I.; et al. Cytotoxic Oleane-Type Triterpene Saponins from Glochidion Eriocarpum. Arch. Pharm. Res. 2012, 35, 19-26. [CrossRef] [PubMed]

45. Singhania, A.; Grueber, W.B. Development of the Embryonic and Larval Peripheral Nervous System of Drosophila. Wires Dev. Biol. 2014, 3, 193-210. [CrossRef]

46. Subramanian, A.; Siefert, M.; Banerjee, S.; Vishal, K.; Bergmann, K.A.; Curts, C.C.M.; Dorr, M.; Molina, C.; Fernandes, J. Remodeling of Peripheral Nerve Ensheathment during the Larval-to-Adult Transition in Drosophila. Dev. Neurobiol. 2017, 77, 1144-1160. [CrossRef]

47. Kounatidis, I.; Chtarbanova, S. Role of Glial Immunity in Lifespan Determination: A Drosophila Perspective. Front. Immunol. 2018, 9. [CrossRef] [PubMed]

48. Angelova, P.R.; Abramov, A.Y. Role of Mitochondrial ROS in the Brain: From Physiology to Neurodegeneration. FEBS Lett. 2018, 592, 692-702. [CrossRef]

49. Barres, B.A. Five Electrophysiological Properties of Glial Cells. Ann. N. Y. Acad. Sci. 1991, 633, 248-254. [CrossRef]

50. Pfrieger, F.W.; Barres, B.A. What the Fly's Glia Tell the Fly's Brain. Cell 1995, 83, 671-674. [CrossRef]

51. Barres, B.A.; Raff, M.C. Axonal Control of Oligodendrocyte Development. J. Cell Biol. 1999, 147, 1123-1128. [CrossRef]

52. Eroglu, C.; Barres, B.A. Regulation of Synaptic Connectivity by Glia. Nature 2010, 468, 223-231. [CrossRef]

53. Allen, N.J.; Lyons, D.A. Glia as Architects of Central Nervous System Formation and Function. Science 2018, 362, 181-185. [CrossRef]

54. Freeman, M.R. Drosophila Central Nervous System Glia. Cold Spring Harb. Perspect. Biol. 2015, 7, a020552. [CrossRef]

55. Sasse, S.; Neuert, H.; Klämbt, C. Differentiation of Drosophila Glial Cells. Wires Dev. Biol. 2015, 4, 623-636. [CrossRef] [PubMed]

56. Yildirim, K.; Petri, J.; Kottmeier, R.; Klämbt, C. Drosophila Glia: Few Cell Types and Many Conserved Functions. Glia 2019, 67, 5-26. [CrossRef] [PubMed]

57. Hindle, S.J.; Bainton, R.J. Barrier Mechanisms in the Drosophila Blood-Brain Barrier. Front. Neurosci. 2014, 8. [CrossRef] [PubMed]

58. Limmer, S.; Weiler, A.; Volkenhoff, A.; Babatz, F.; Klämbt, C. The Drosophila Blood-Brain Barrier: Development and Function of a Glial Endothelium. Front. Neurosci. 2014, 8. [CrossRef]

59. Von Hilchen, C.M.; Bustos, A.E.; Giangrande, A.; Technau, G.M.; Altenhein, B. Predetermined Embryonic Glial Cells Form the Distinct Glial Sheaths of the Drosophila Peripheral Nervous System. Development 2013, 140, 3657-3668. [CrossRef]

60. Navarro, J.A.; Ohmann, E.; Sanchez, D.; Botella, J.A.; Liebisch, G.; Moltó, M.D.; Ganfornina, M.D.; Schmitz, G.; Schneuwly, S. Altered Lipid Metabolism in a Drosophila Model of Friedreich's Ataxia. Hum. Mol. Genet. 2010, 19, 2828-2840. [CrossRef]

61. Bailey, A.P.; Koster, G.; Guillermier, C.; Hirst, E.M.A.; MacRae, J.I.; Lechene, C.P.; Postle, A.D.; Gould, A.P. Antioxidant Role for Lipid Droplets in a Stem Cell Niche of Drosophila. Cell 2015, 163, 340-353. [CrossRef]

62. Cabirol-Pol, M.-J.; Khalil, B.; Rival, T.; Faivre-Sarrailh, C.; Besson, M.T. Glial Lipid Droplets and Neurodegeneration in a Drosophila Model of Complex I Deficiency. Glia 2018, 66, 874-888. [CrossRef] [PubMed]

63. Sunderhaus, E.R.; Law, A.D.; Kretzschmar, D. ER Responses Play a Key Role in Swiss-Cheese/Neuropathy Target EsteraseAssociated Neurodegeneration. Neurobiol. Dis. 2019, 130, 104520. [CrossRef] [PubMed] 
64. Verheggen, I.C.M.; de Jong, J.J.A.; van Boxtel, M.P.J.; Gronenschild, E.H.B.M.; Palm, W.M.; Postma, A.A.; Jansen, J.F.A.; Verhey, F.R.J.; Backes, W.H. Increase in Blood-Brain Barrier Leakage in Healthy, Older Adults. GeroScience 2020, 42, 1183-1193. [CrossRef] [PubMed]

65. Nation, D.A.; Sweeney, M.D.; Montagne, A.; Sagare, A.P.; D’Orazio, L.M.; Pachicano, M.; Sepehrband, F.; Nelson, A.R.; Buennagel, D.P.; Harrington, M.G.; et al. Blood-Brain Barrier Breakdown Is an Early Biomarker of Human Cognitive Dysfunction. Nat. Med. 2019, 25, 270-276. [CrossRef]

66. Zlokovic, B.V. The Blood-Brain Barrier in Health and Chronic Neurodegenerative Disorders. Neuron 2008, 57, 178-201. [CrossRef] [PubMed]

67. Melentev, P.A.; Agranovich, O.E.; Sarantseva, S.V. Human diseases associated with NTE gene. Ecol. Genet. 2020, 18, 229-242. [CrossRef]

68. McFerrin, J.; Patton, B.L.; Sunderhaus, E.R.; Kretzschmar, D. NTE/PNPLA6 Is Expressed in Mature Schwann Cells and Is Required for Glial Ensheathment of Remak Fibers. Glia 2017, 65, 804-816. [CrossRef] 